\title{
A family study of craniosynostosis, with probable recognition of a distinct syndrome
}

\author{
CO CARTER, * K TILL, $\dagger$ VERONICA FRASER,* AND REBECCA COFFEY* \\ From * the MRC Clinical Genetics Unit, Institute of Child Health, and †the Neurosurgical Unit, \\ The Hospital for Sick Children, Great Ormond Street, London WC1
}

SUMmaRY A family study was based on 184 consecutive patients who had undergone surgery for craniosynostosis at The Hospital for Sick Children, London, between 1953 and 1976. Of these, 127 were traced and visited and are the probands for this study. Crouzon syndrome was recognised in 16, Apert in 11, Saethre-Chotzen in nine, and Pfeiffer in two. In addition, two probands had Saethre-Chotzen-like facies and bilaterally broad big toes owing to partial or complete duplication of the distal phalanx. This syndrome is distinct from Pfeiffer syndrome, in which the facies more closely resembles that in Crouzon syndrome and in which it is the proximal phalanx of the big toe (and often of the thumb) which is abnormal. It is suggested that this newly recognised syndrome be called after Robinow and Sorauf, who appear to be the first to have described a family with the condition.

One proband with coronal stenosis had a mother and brother affected, but no syndrome was recognised in them. Excluding this last case, no non-syndromic proband had an affected parent. The 58 probands with predominantly sagittal synostosis had 106 sibs, none of whom was affected. The 21 probands with predominantly coronal synostosis included one sib pair both affected; the remaining 17 sibs were unaffected. The four probands with predominantly metopic stenosis had 13 unaffected sibs and the four with multiple sutures involved had eight unaffected sibs. One sagittal proband had an unaffected monozygotic twin and another an unaffected dizygotic twin.

There are four well-defined dominant syndromes involving craniosynostosis, ${ }^{1}$ Apert, Crouzon, Saethre-Chotzen, and Pfeiffer, as well as many uncommon ones. ${ }^{2}$ However, the extent of genetic determination and empirical recurrence risks are not well-established where the craniosynostosis is not obviously part of a syndrome and is of a degree sufficient for the patient to be referred to a neurosurgeon. One informative family study has been published. ${ }^{3}$ We report a further study based on a consecutive series of patients referred to the neurosurgical unit of The Hospital for Sick Children, London, over the period 1953 to 1976.

\section{Material and methods}

There were 184 such patients, of whom nine were dead, 17 were abroad, 11 were non-cooperators (either the general practitioner advised against getting in touch with the family or the family were

Received for publication 2 November 1981 unwilling to be visited), and 20 were not traced. Full information was available on 127. The surgical notes recorded mainly the sutures involved, but did not usually attempt to define a syndrome. All were treated by craniectomy, except for three sagittal, one unicoronal, and four metopic cases.

The families of these 127 index patients were visited (by VF or RC), a family history taken, and measurements taken from the parents and from most of the sibs. The measurements included skull length, skull width, and interpupillary and intermedial canthus distance. Photographs were available in the medical records for some of the patients, and most of the patients with syndromes had been seen by COC before this survey, when they were in the ward or when referred for genetic counselling. When the photographs or medical records suggested, or VF or RC suspected, a specific syndrome, or when a relative was affected, or when the measurements of the relative suggested that he or she might be affected, the patient and family were seen by COC. 
TABLE 1 Subdivision of cases of craniosynostosis

\begin{tabular}{llrr}
\hline & Male & Female \\
\hline Syndromic & & & \\
& Crouzon & 11 & 5 \\
& Apert & 8 & 3 \\
& Saethre-Chotzen & 2 & 7 \\
& Pfeiffer & 1 & 1 \\
& Robinow-Sorauf & 1 & 1 \\
Non-syndromic & & \\
& Sagittal & 50 & 8 \\
& Coronal & 9 & 12 \\
& Metopic & 3 & 1 \\
& Multiple & 2 & 2 \\
\hline
\end{tabular}

\section{Findings}

The numbers of each type are summarised in table 1 .

\section{SPECIFIC SYNDROMES}

Crouzon syndrome was recognised in $16(11$ male and five female) patients of the 127. The most striking and constant features distinguishing this syndrome are proptosis and maxillary hypoplasia. In seven instances neither parent was affected, in two instances the father, and in seven the mother. The seven sporadic cases had 11 sibs all unaffected. The nine index patients with an affected parent had 20 surviving sibs of whom six were affected. In addition, two index patients with an affected mother had a maternal half-sib, both of whom were affected. The segregation ratio where one parent was affected, by the Weinberg proband method, was therefore 8 in 22 , reasonably close to the expected $0 \cdot 5$. The sporadic cases may plausibly be regarded as being the result of fresh mutation. The most extensive pedigree of Crouzon disease is that of index patient 4. This family has been fully reported with photographs by Vulliamy and Normandale. $^{5}$

Apert syndrome was recognised in 11 patients (eight male and three female). The most striking and constant features in addition to the severe craniosynostosis were severe syndactyly and brachydactyly of the hands and feet involving at least the second to fifth digits and with short malformed first digits. The syndactyly was usually in part osseous as well as cutaneous. All 11 cases occurred sporadically, with the parents and all 23 sibs unaffected. This is compatible with dominant inheritance with all cases resulting from fresh mutation.

Saethre-Chotzen syndrome was recognised in nine patients (two male and seven female). This syndrome had not been clearly recognised until recently. Although Saethre's and Chotzen's reports were in 1931 and 1932, respectively, the first reports from North America were in $1970 .^{6} 7$ No such patients were identified in the large series reported

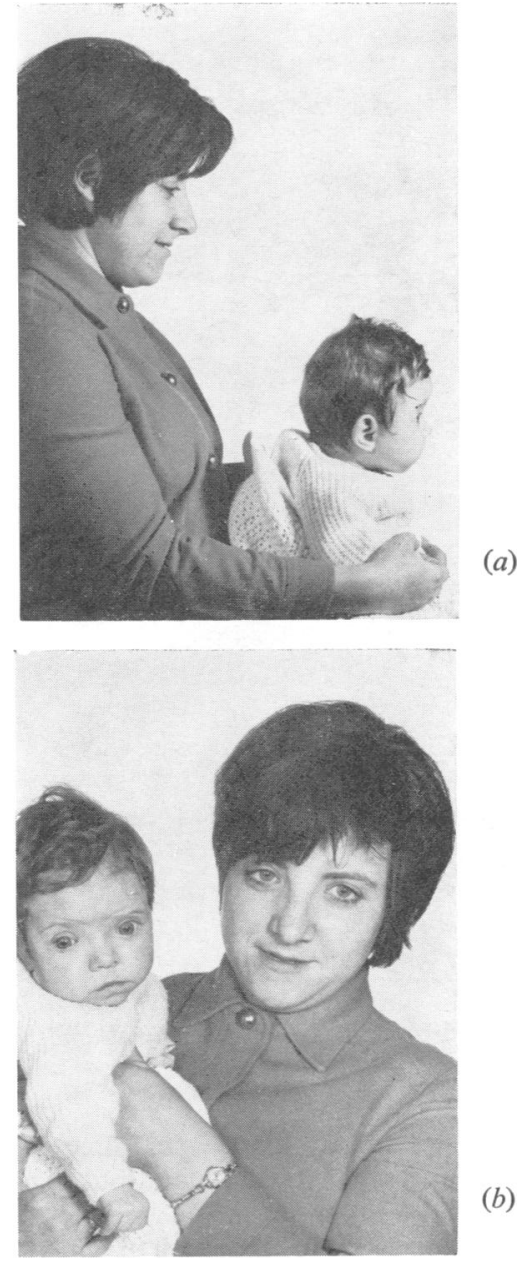

FIG 1 ( $\mathrm{a}$ and $\mathrm{b})$ Saethre-Chotzen syndrome; only the daughter has had craniectomy.

by Hunter and Rudd from Toronto. ${ }^{34}$ The forehead may be relatively high and narrow in this syndrome, ptosis, facial asymmetry, and high narrow palate are often present, and there is marked telecanthus but little true hypertelorism. A valuable sign is the long and prominent ear crus. ${ }^{1}$ A mother and child are shown in fig 1 and a younger child in fig 2 . There may be mild cutaneous syndactyly of the index and middle fingers and the second, third, and fourth toes, clinodactyly of the little finger, and usually mild brachydactyly. In five instances neither parent was affected and in three families (with four index patients) the mother was affected. The five sporadic cases had six sibs, all unaffected. The four index patients with an affected mother had 


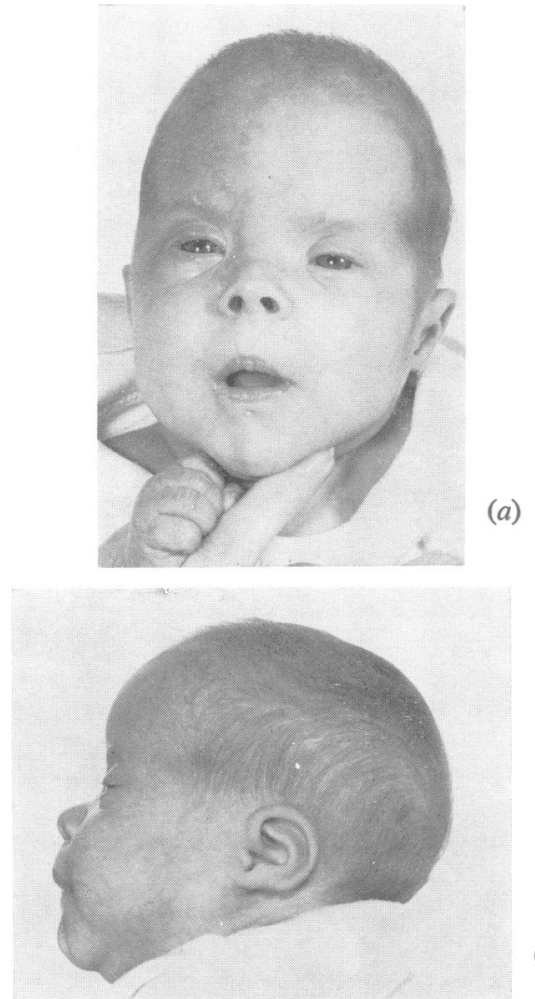

(a)

FIG 2 (a and b) Saethre-Chotzen syndrome; girl aged 12 weeks.

eight sibs, of whom two were affected, and no half-sibs. Inheritance is dominant, but the syndrome is particularly variable in its manifestation, and there is a suggestion of incomplete penetrance both from the low proportion (two in eight) of sibs affected where the mother was also affected, and the proportion (five in nine) of cases with neither parent affected and so apparently the result of fresh mutation. This proportion is high for a condition which probably does not much reduce reproductive fitness. A clearly dominant family with SaethreChotzen syndrome has been seen in a patient admitted since this series was completed. The patient, her father, her father's sister, and father's sister's son were all affected, but only the patient required operation.

Pfeiffer syndrome was recognised in only two patients and both were sporadic. The facial features resemble those of Crouzon syndrome. The most characteristic features are the broad thumbs and big toes and valgus deformity of the big toes, but these may be present in only mild or partial degree and can easily be missed. Conversely, the hand and foot abnormalities may be severe in patients with little craniosynostosis. A family, of which the index patient was seen in the neurosurgical clinic after the end of this survey, has been reported with photographs. ${ }^{8}$ In this family the hand and foot abnormality was seen clearly in the mother, whose head shape suggested only mild craniosynostosis, but was less marked in her son who required craniectomy. The abnormality of the thumb and big toe is especially of the proximal phalanx, giving rise to the valgus deformity. The terminal phalanx is broad but not split. The first metatarsal may also be broad and misshapen.

Two patients had a different association of craniosynostosis and thumb abnormalities from that seen in Pfeiffer syndrome. The big toes were broad, but in one patient they were straight and in the other valgus. The deformity was a widening and near duplication of the terminal phalanx. The facial features resembled those of the SaethreChotzen syndrome with narrow forehead, facial asymmetry, prominent earcrus, and telecanthus rather than hypertelorism. The face and foot of one child are shown in fig 3, and a side-view of the face and radiograph of one foot of the other child in fig 4 .

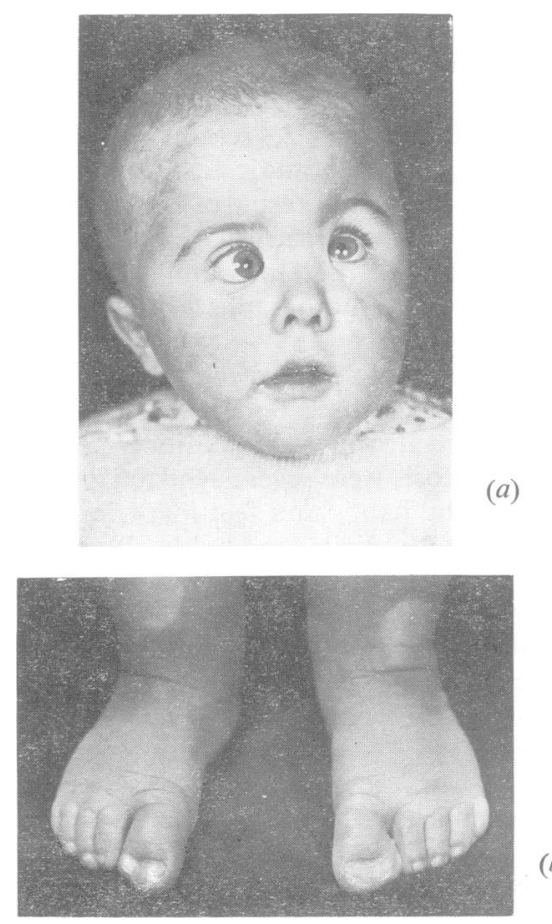

FIG 3 (a and b) Robinow-Sorauf syndrome; face and feet of girl aged 18 weeks. 


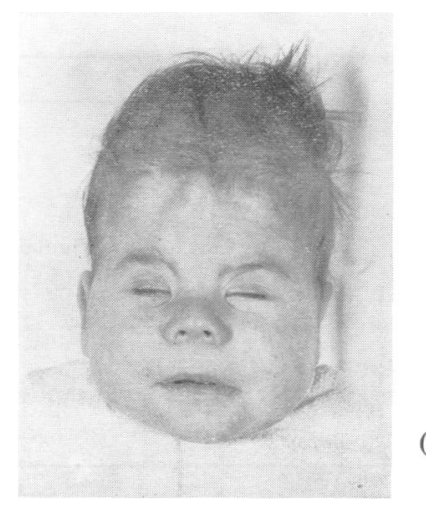

sporadic and none of the 106 sibs was affected. Bicoronal synostosis was present in 12 (four male and eight female) index patients. Of these, 11 were born to normal parents and they had nine sibs of whom one had unicoronal synostosis. The remaining index patient, a girl, had an affected mother and also a brother with coronal and sagittal synostosis. Unicoronal synostosis was present in nine (five male and four female) index patients. All parents were unaffected and of ten sibs one was the index patient with bicoronal synostosis mentioned above. The metopic suture synostosis was present in four (three male and one female) patients. All occurred sporadically and they had 13 unaffected sibs. Nonspecific multiple synostosis was present in four (two male and two female) index patients; all occurred sporadically and they had eight unaffected sibs.

Two index patients with sagittal synostosis were twin-born. One pair were almost certainly monozygotic from clinical photographs, and the other were certainly monozygotic (seen by $\mathrm{COC}$ ), both pairs discordant for craniosynostosis. The untraced index patients included one concordant pair, from clinical photographs almost certainly monozygotic, one unlike-sex discordant dizygotic pair, and one pair of unknown zygosity, the twin having died at 10 days. In each case the index patient had sagittal synostosis. No patients with coronal synostosis were twin-born.

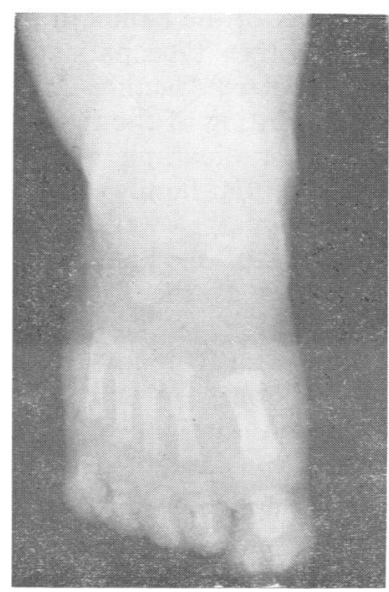

\section{Discussion}

It is apparent from this survey that once the dominant syndromes, Crouzon, Saethre-Chotzen, Apert, and Pfeiffer, and the further syndrome with a broad and split terminal phalanx of the hallux are excluded, the overall risk of recurrence is small when neither parent is affected; however, the recurrence risk is probably greater for coronal than sagittal synostosis. None of the over 100 sibs of the 58 index patients with sagittal synostosis in this series was affected. In the series of Hunter and Rudd ${ }^{3}$ from Canada based on 214 index patients the total number of sibs is not stated (in one family both sibs were index patients), but is likely to be at least 250 . In their series only four sibs and a dizygotic twin were affected, apart from the family where the mother was affected. The empirical recurrence risk after sagittal synostosis appears, therefore, to be of the order of $1 \%$.

In the case of coronal synostosis, in our series, excluding the family with an affected mother, only two (both index patients in a single family) in 19 sibs of the 20 index patients were affected. In the series of Hunter and Rudd, ${ }^{4}$ of some 84 index patients (after exclusion of Crouzon and other 
TABLE 2 Features distinguishing four dominant craniosynostosis syndromes

\begin{tabular}{|c|c|c|c|c|}
\hline & Crouzon & Saethre-Chotzen & Pfeiffer & Robinow-Sorauf \\
\hline Forehead & Broad & Often high & Broad & Often high \\
\hline Maxillary hypoplasia & ++ & + & + & - \\
\hline Hypertelorism & $+t$ & - & ++ & - \\
\hline Ptosis & - & + & - & + \\
\hline Proptosis & ++ & - & + & - \\
\hline Nasal bridge & Normal & Low, flat nasofrontal angle & Normal & Low, flat nasofrontal angle \\
\hline Telecanthus & - & + & - & + \\
\hline Ear crus & Normal & Prominent, long & Normal & Prominent, long \\
\hline Cleft palate & & \pm & \pm & High, narrow \\
\hline Pollux & Normal & Normal & Varus, abnormal proxima lphalanx & Normal \\
\hline Hallux & Normal & Normal & Varus, abnormal proximal phalanx & Valgus or straight, split distal phalanx \\
\hline $\begin{array}{l}\text { Syndactyly, } \\
\text { soft tissue }\end{array}$ & - & $\begin{array}{l}2 / 3 \text { hands } \\
3 / 4 \text { toes }\end{array}$ & $\begin{array}{l}2 / 3 \text { hands } \\
3 / 4 \text { toes }\end{array}$ & $\begin{array}{l}2 / 3 \text { hands } \\
3 / 4 \text { toes }\end{array}$ \\
\hline
\end{tabular}

syndromes) with predominantly coronal synostosis, six sibs were affected out of some 140 where parents were unaffected (their figure is four sibs affected, but this was counting one family only once where there were two affected sibs, both index patients). The empirical recurrence risk therefore for coronal synostosis, where neither parent is affected, is of the order of $5 \%$.

A noteworthy feature of the present series is the frequency of the Saethre-Chotzen syndrome. The higher proportion of apparently dominant families with coronal synostosis in Hunter and Rudd's series is perhaps due to their inclusion of this and other syndromes in the coronal group, though they separate Crouzon syndrome. The authors draw attention to the family patterns of minor dysmorphic features, often involving the hands, in their families $1,4,8$, and 9 . Their family 1 is possibly an example of the midline split-face syndrome. Their family 4 , with patients with ptosis, camptodactyly of the fourth and fifth fingers and short fifth finger, simian creases, and distal axial triradii, is probably an example of Saethre-Chotzen syndrome. This is possibly also the diagnosis in families 8 and 10 .

The two patients with the association of craniosynostosis and broad big toes, of a type different from that seen in Pfeiffer syndrome, are of special interest and constitute, we think, a distinct syndrome. Similar patients, all with apparent dominant inheritance, have been reported by Robinow and Sorauf ${ }^{9}$ from North America, under the title of Noack syndrome, by Naveh and Friedman ${ }^{10}$ from Israel, under the title of Pfeiffer syndrome, and recently by Kopyšć et $a l^{11}$ from Poland, under the title of Saethre-Chotzen syndrome. The last authors, independently of ourselves, recognised the facial similarity to Saethre-Chotzen cases. But, since in the American, Israeli, and Polish families the abnormality of the distal phalanx of the big toe was apparently present, to some degree, consistently in affected members of the families, the condition is almost certainly genetically distinct from SaethreChotzen. The thumb is normal. Pfeiffer patients, though showing much between and within family variation, consistently have the first, rather than the second, phalanx of the big toe (and often of the thumb) affected, and their facial features resemble those in the Crouzon rather than the SaethreChotzen syndrome. ${ }^{12}$ The family described by Noack $^{13}$ is probably not the same since both phalanges of the hallux and the first metatarsal were split bilaterally. We suggest that the dominant syndrome with Saethre-Chotzen facies and split terminal phalanx of the hallux should be called the Robinow-Sorauf syndrome.

There is, however, a need for further studies of the terminal phalanx of the hallux in this syndrome and in Saethre-Chotzen type patients. The radiograph of one reported Saethre-Chotzen patient shows a minimal splitting of the tip of the terminal phalanx,${ }^{14}$ and the radiograph of one patient in Robinow and Sorauf's family ${ }^{9}$ shows a partial splitting of the proximal, as well as full splitting of the terminal, phalanx of one hallux.

The main features of the four syndromes are summarised in table 2.

A further family with Robinow-Sorauf syndrome is reported from South Wales by Young and Harper, ${ }^{15}$ once again with the abnormality of the distal phalanx and the straight or valgus hallux in at least five of the six affected individuals.

\section{References}

1 Smith D. Recognisable patterns of human malformations. 2nd ed. Philadelphia: Saunders, 1976.

2 Cohen MM. Genetic perspectives in craniosynostosis and syndromes associated with craniosynostosis. J Neurosurg 1976;47:886-98.

3 Hunter AGW, Rudd NL. Craniosynostosis I. Sagittal synostosis; its genetics and associated clinical findings in 214 patients who lacked involvement of the coronal suture(s). Teratology 1976;14:185-94.

4 Hunter AGW, Rudd NL. Craniosynostosis JI. Coronal synostosis; its familial characteristics and associated 
clinical findings in 109 patients lacking bilateral polysyndactyly or syndactyly. Teratology 1977;15:301-10.

5 Vulliamy DG, Normandale PA. Craniofacial dysostosis in a Dorset family. Arch Dis Child 1966;41:375-82.

6 Aase JM, Smith DW. Facial asymmetry and abnormalities of palms and ears; a dominantly inherited developmental syndrome. J Pediatr 1970;76:928-30.

7 Bartsocas CS, Weber AL, Crawford JD. Acrocephalosyndactyly type III : Chotzen's syndrome. J Pediatr 1970; 77:267-72.

8 Baraitser $M$, Bowen-Bravery $M$, Saldana-Garcia $P$. Pitfalls of genetic counselling in Pfeiffer's syndrome. J Med Genet 1980;17:250-6.

9 Robinow M, Sorauf TJ. Acrocephalopolysyndactyly, type Noack, in a large kindred. Birth Defects 1975;11/5: 99-106.

10 Naveh Y, Friedman A. Pfeiffer syndrome: report of a family and a review of the literature. J Med Genet 1976; 13:277-80.
11 Kopyšč Z, Stañska M. Ryżko J, Kulczyk B. The SaethreChotzen syndrome with partial bifid of the distal phalanges of the great toes. Hum Genet 1980;56:195-204.

12 Pfeiffer RA. Associated deformities of the head and hands. Birth Defects 1969;V/3:18-34.

13 Noack M. Ein Beitrag zum Krankheitbild der Akrocephalosyndactylie (Apert). Arch Kinderheilkd 1959;160: 168-71.

14 Pruzansky S, Pashayan H, Kreiborg S, Miller M. Roentgenographic studies of the premature craniofacial synostoses; report of a family with Saethre-Chotzen syndrome. Birth Defects 1975;11/2:226-37.

15 Young ID, Harper PS. An unusual form of familial acrocephalosyndactyly. J Med Genet 1982;19:286-8.

Requests for reprints to Professor C O Carter, MRC Clinical Genetics Unit, Institute of Child Health, 30 Guilford Street, London WCIN 1EH. 